\title{
Quem participa em quê? Experiências de construção compartilhada no âmbito da cooperação Brasil - Canadá para o Aperfeiçoamento da Gestão na Atenção Primária à Saúde'
}

\section{Who takes part in what? Experiences of shared construction in Brazil-Canada cooperation for the Improving Management in Primary Health Care}

\author{
José Ivo Pedrosa \\ Doutor em Saúde Coletiva. Professor Associado do Departamento \\ de Medicina Comunitária da Universidade Federal do Piauí. Ge- \\ rente do Núcleo de Estudos em Saúde Pública/UFPI. \\ Endereço: Campus Universitário Petrônio Portela. SG 7, Ininga, CEP \\ 64049-550, Teresina, PI, Brasil. \\ E-mail: jivopedrosaळgmail.com \\ Maria Fátima de Sousa \\ Doutora em Ciências da Saúde. Professora Adjunta do Departamen- \\ to de Saúde Coletiva da Universidade de Brasília. Coordenadora \\ do Núcleo de Estudos em Saúde Pública/UnB. \\ Endereço: SCLN 406; Bloco A, 20 Andar, Asa Norte, CEP 70847-510, \\ Brasília, DF, Brasil. \\ E-mail: fatimasousa®unb.br

\section{Edgar Merchán Hamann} \\ Doutor em Saúde Pública. Professor Adjunto do Departamento de \\ Saúde Coletiva da Universidade de Brasília. Pesquisador do Núcleo \\ de Estudos em Saúde Pública/UnB. \\ Endereço: SCLN 406, Bloco A, 20 Andar, Asa Norte, CEP 70847-510, \\ Brasília, DF, Brasil. \\ E-mail: hamann®unb.br

\section{Dais Gonçalves Rocha} \\ Doutora em Saúde Pública. Professora Adjunta do Departamento \\ de Saúde Coletiva da Universidade de Brasília. Pesquisadora do \\ Núcleo de Estudos em Saúde Pública/UnB. \\ Endereço: SCLN 406, Bloco A, 20 Andar, Asa Norte, CEP 70847-510, \\ Brasília, DF, Brasil. \\ E-mail: daisrochaळyahoo.com.br
}

\author{
Maria Alice Araújo Oliveira \\ Doutora em Nutrição. Professora Associada da Universidade \\ Federal de Alagoas. \\ Endereço: Rua Empresário Carlos da Silva Nogueira no 16 ap. 204, \\ Jatiúca, CEP 57036-540 Maceió, AL, Brasil. \\ E-mail: alicemczœsupertig.com.br \\ I Financiamento: Projeto de Cooperação Brasil/Canadá para o \\ Aperfeiçoamento da Gestão em Atenção Primária
}




\section{Resumo}

$\mathrm{O}$ artigo analisa processos e resultados da construção compartilhada de conhecimento e intervenção no Projeto de Aperfeiçoamento da Gestão da Atenção Primária (AGAP) desenvolvido no âmbito da cooperação Brasil e Canadá em quatro Estados da região Nordeste do País, utilizando metodologia de avaliação com enfoque nos alcances e aprendizagens, que tem como pressuposto a cooperação e participação das partes, preconiza a triangulação mediante a combinação de abordagens e de técnicas qualitativa e quantitativa caracterizada como multimétodos, a partir da identificação dos momentos que significaram encontros de compartilhamento, elementos que dificultaram ou facilitaram este processo e das lições apreendidas. A pesquisa avaliativa compreendeu análise documental, observação de encontros presenciais, oficina com o Comitê Gestor de Avaliação para apresentação e pactuação da proposta, oficinas de avaliação com os projetos locais, observação de unidades de saúde nos municípios, entrevistas semiestruturadas com sujeitos estratégicos dos níveis locais, regionais, nacional e internacional. Os resultados demonstraram que a relação de cooperação Brasil/Canadá é promissora, entretanto precisa ser construída de forma mais cooperada e dialogada em que os objetos da cooperação sejam construídos de forma compartilhada.

Palavras-chave: Construção compartilhada; Atenção primária em saúde; Cooperação internacional.

\section{Abstract}

The article examines processes and outcomes of the shared construction of knowledge and intervention in the Project for Improving Management of Primary Health Care (AGAP) developed cooperatively between Brazil and Canada. It involves four states in the Northeast region, uses the evaluation methodology with focus on achievements and learning and presupposes the cooperation and participation of stakeholders; the project, characterized as using multi methods, advocates triangulation through a combination of quantitative and qualitative approaches and techniques after identifying the moments in which sharing encounters happened, as well as the elements which hinder or facilitate this process and lessons learned. Evaluative research used the following methodology: document analysis; observation of meetings; workshop with the Evaluation Steering Committee for presentation and agreement of the proposal submitted; evaluation workshops on local projects, observation of health care services in the municipalities, semi-structured interviews with strategic interlocutors of local, regional, national and international levels. The results showed that the cooperation relationship between Brazil and Canada is promising, but needs to be built in a more cooperative and dialogical way, in which objects of cooperation are constructed in a shared form.

Keywords: Collective Construction; Primary Health Care; International Cooperation. 


\section{Introdução}

Participação social, valor ético fundante do projeto de modernidade das sociedades ocidentais, presente desde o século XVI à conformação dos estados modernos e democráticos, base de utopias igualitárias pautadas nos ideais de democracia e cidadania, representou o dispositivo agregador do movimento pela democratização política no Brasil e ampliação dos direitos sociais, dentre os quais se encontra o direito à saúde. Premissa básica afirmada por Santos (2006) de que a opção pelas democracias requer o compromisso e o anseio de recriação dos espaços e mecanismos de participação social instituídos e instituintes, uma vez que as relações sociais imprimem a dinâmica do processo democrático.

No Brasil atual, a participação da sociedade acontece em espaços institucionalizados como conselhos de direitos de caráter deliberativo em relação às políticas públicas e não institucionalizados no âmbito da sociedade civil, assim como em espaços da gestão relacionados à formação de colegiados para tomada de decisões, planejamento e avaliação.

Esta amplitude e diversidade de participação da sociedade brasileira após a democratização apresentam em comum a ideia de que para participar é imprescindível o diálogo entre os envolvidos em determinada temática, o trabalho de grupos e a produção de resultados construídos neste diálogo, no qual as diferenças e interesses são pactuados. Observa-se nas diversas expressões de democracia participativa (Avritzer, 200o) a construção compartilhada, como produto e como processo, na formulação de políticas e pactos, programas, projetos e ações, além da produção intersubjetiva que diz respeito a afetos, emoções, motivações e desejos.

No âmbito dos processos de intercâmbio Brasil/ Canadá, realizado em 4 Estados do Nordeste Brasileiro, o projeto AGAP (Aperfeiçoamento da Gestão da Atenção Primária à Saúde - Fortalecendo a Atenção Primária à Saúde no Brasil e no Canadá: um Projeto para o Intercâmbio de Conhecimento para a Equidade) preconizava a participação de instituições, técnicos, gestores e comunidades em projetos de intervenção construídos de forma compartilhada. Concebido desde 2003 em rede de parceiros, cujos líderes foram o Conselho Nacional de Secretários de Estado da Saúde (CONASS), a Universidade de Toronto, no Canadá, e o Ministério da Saúde (MS), através do Departamento de Atenção Básica (DAB), com a participação da Sociedade Brasileira de Medicina de Família e Comunidade, da Organização Pan-Americana de Saúde (OPAS), no Brasil, da Biblioteca Virtual em Saúde (BIREME/OPAS), a Agência Canadense de Desenvolvimento Internacional (CIDA) como principal financiador e, juntamente com a Agência Brasileira de Cooperação (ABC) aprovaram o documento do projeto em 2007.

As reflexões aqui apresentadas têm por base a pesquisa de avaliação quali-quantitativa do Projeto AGAP realizada pela equipe de pesquisadores do Núcleo de Estudos de Saúde Pública (NESP), do Centro de Estudos Avançados Multidisciplinares (CEAM) da Universidade de Brasília (UnB), em rede colaborativa de pesquisadores das Universidades Federais do Piauí, Alagoas, Paraíba e Secretaria Municipal de Saúde de Fortaleza-CE.

Neste artigo discutimos o processo de construção compartilhada preconizado para o desenvolvimento do projeto por meio da identificação dos elementos que dificultaram ou facilitaram esse processo, as lições apreendidas e os resultados vivenciados, com base nos resultados das oficinas de avaliação realizadas com as equipes participantes nos Estados brasileiros envolvidos e nas entrevistas realizadas com atores estratégicos.

\section{Projeto AGAP e estados participantes}

O AGAP foi idealizado com base na decisão dos gestores estaduais em estabelecer o fortalecimento da Atenção Primária em Saúde (APS) como prioridade nacional, diante da situação da APS no Brasil que mostra reduzida alteração e diversidade de indicadores de saúde entre regiões e Estados brasileiros, gestores com pouco conhecimento, inexistência de cooperação entre níveis de gestão, não integração entre áreas técnicas e necessidade de mudanças que compreendam a responsabilização e compromisso de gestores na defesa da APS no sentido de aperfeiçoar sua configuração no sistema de saúde brasileiro, na qualificação da atenção e na diminuição das iniquidades no Brasil. 
Caracteriza-se por relação cooperativa entre parceiros no Brasil e no Canadá, em torno da APS, apresenta a intencionalidade de promover a equidade em saúde, compartilhar o conhecimento e desenvolver capacidades nas equipes gestoras locais, com objetivos específicos de aperfeiçoar a gestão da APS no Brasil através da instrumentalização de gestores estaduais, municipais e integração entre os vários níveis de gestão e áreas técnicas (vertical e horizontal), reestruturar o planejamento, a alocação de recursos e a prestação de contas em todos os níveis de gestão, refletindo os princípios e valores da APS, incorporados ao Sistema Único de Saúde - SUS (equidade social, igualdade de gênero e etnia), melhorar a qualidade e a utilização da informação disponível em todos os níveis do sistema APS e reforçar e diversificar as relações de troca de conhecimento entre Brasil e Canadá.

A cooperação entre os parceiros contempla interesses inerentes à missão de cada instituição e expectativas concordantes particularmente em torno dos resultados esperados. Os gestores brasileiros articulam-se em torno do fortalecimento da APS em termos de processos de gestão e infraestrutura, além do desejo de construir liderança internacional, enquanto os parceiros do Canadá apresentam expectativas de produzir conhecimentos, fomentar intercâmbio técnico-científico, desenvolver tecnologias de informação e implementar ações voltadas para promoção da equidade em saúde expressas como pré-requisito pela CIDA (CONASS, 2011).

A gestão do projeto é feita pelo Conselho de Gestão, Conselho Executivo e Grupo Assessor com representações do Brasil e do Canadá. Em janeiro de 2007, é aprovado e em março de 2008 são definidos os Estados nordestinos que deverão participar, com base em indicadores do Sistema de Informação da Atenção Básica (SIAB) sendo em seguida os gestores sensibilizados para a adesão e contrapartida.

Na região Nordeste, participaram os Estados de Alagoas, população de 3.037.203 habitantes, 102 municípios, PIB per capita de R\$ 6.227,oo e ÍDH de o,677 (IBGE, 2008), cobertura de 95,2\% de Equipes do Programa de Saúde da Família, envolvendo 8 municípios incluindo a capital Maceió; Ceará, com 8.547.809 habitantes, 184 municípios, PIB per capita de R\$ 7.112,oo, IDH o,723 (IBGE, 2008), 1.195 equi- pes de Saúde da Família implantadas com cobertura populacional de 59,6\%, último Estado a se inserir no AGAP em julho de 2009 e só assina o contrato de implantação em fevereiro de 2010, participa com 9 municípios; Paraíba, 3.769.977 habitantes, 223 municípios, PIB per capita de R\$ 6.866,oo, IDH o,718 (IBGE, 2008), 1.195 equipes de Saúde da Família implantadas, cobertura populacional de 95,2\% e 9 municípios participaram do AGAP; Piaúí, população de 2.974.479 habitantes distribuída em 223 municípios, PIB per capita de R\$5.372,00, IDH de o,703, o mais baixo da Região Nordeste e um dos menores do País (IBGE, 2008), apresenta 720 equipes de Saúde da Família implantadas, cobertura populacional de 97,7\%, com 9 municípios participantes.

A estratégia de implantação contemplava a adesão dos gestores estaduais, seleção dos municípios e dos técnicos participantes, oficinas de educação permanente para a construção do problema e dos projetos de intervenção, encontros de monitoramento para implementar, avaliar a intervenção e participar em eventos no Brasil e no Canadá.

A educação permanente consistiu de quatro oficinas abordando a apreensão dos conceitos básicos de Atenção Primária em Saúde e seus atributos, uso de informações, utilização da matriz lógica para a construção de problemas e do plano de ação, evidências como ferramentas de monitoramento e avaliação.

\section{Participação e construção compartilhada}

No contexto atual, a participação dos indivíduos na vida social compreende mecanismos formais como o voto popular, a presença de grupos da sociedade nas decisões a respeito de problemas que afetam a vida cotidiana, a inclusão nos espaços de diálogo de sujeitos antes considerados sem atributos para tal e a participação direta dos atores envolvidos em determinadas questões para sua elucidação e construção de estratégias de enfrentamento.

A capilaridade dos espaços e processos participativos na vida social abre possibilidades para o exercício da ação comunicativa desde o âmbito macro social, entre necessidades de saúde e possibilidades de resolvê-las em prol da coletividade, até 
o nível grupal e organizacional entre as instituições e seus atores envolvidos.

Compreende, portanto a importância da ampliação de espaços públicos e coletivos para o exercício do diálogo e da pactuação de interesses, a produção de uma cultura de participação democrática na gestão de ações, serviços, redes e sistemas de saúde.

Nessa perspectiva, metodologias e estratégias que incentivam a participação ativa dos envolvidos têm sido experimentadas em intervenções no campo da saúde com propósitos, intencionalidades e âmbitos diversos que compreendem a formulação coletiva de políticas, planos, programas, projetos e a gestão participativa na definição, no enfrentamento do problema e na avaliação.

Em sociedades democráticas, o ciclo da formulação à efetividade das políticas públicas compreende a construção da vontade coletiva em relação à temática em questão, isto é, o processo de compreensão, aceitação e mobilização da sociedade; a institucionalização no plano jurídico legal; o desenvolvimento de organizações e arranjos institucionais com capacidade de produzir as ações consensuais e garantidas na lei, e finalmente a avaliação dessa política pela sociedade (Eibenschultz, 1991).

No âmbito mais geral do campo político, a gestão participativa na perspectiva de diminuir a separação entre sociedade civil e Estado implica o aprofundamento de processos que ampliam a participação social nas políticas públicas e a constituição de espaços nos quais são construídas proposições coletivas incluindo as demandas da sociedade e arranjos institucionais necessários para operacionalizar as respostas.

Esses arranjos exigem processos compartilhados de formulação de políticas que minimizem a captura e tradução dos desejos e necessidades da sociedade civil pelos recursos de poder técnico e burocrático apresentados pelo Governo, além de dinamismo organizacional que reduza as distâncias hierárquicas e possibilite momentos de construção da vontade coletiva.

A partir dos anos 9o, emergiram novas políticas e processos de gestão experimentados em uma diversidade de espaços de interação e partilha como conselhos gestores de políticas públicas, orçamentos participativos, câmaras setoriais, redes e fóruns coletivos (Tatagiba, 2009), no sentido da constitui- ção de canais de cogestão com o Estado e construção de agendas comuns ampliando a esfera pública de construção e pactuação das políticas públicas com base na interlocução direta com os envolvidos.

No âmbito particular do SUS, têm-se as conferências nas quais se definem e constroem a vontade coletiva; um sistema jurídico com leis constitucionais e infraconstitucionais que garantem o direito à saúde do cidadão; as experiências inovadoras de gestão e organização para produzir ações de saúde, introduzindo técnicas como diagnóstico e planejamento participativo, avaliação com base em qualidade; e os conselhos de saúde como instâncias avaliadoras e legitimadoras das políticas implementadas.

Esses colegiados com o objetivo de instituir processos de compartilhamento de gestão por meio da participação de sujeitos e grupos nos processos institucionais de formulação, decisão, planejamento, execução e avaliação das políticas, na prática "operam de maneira burocratizada, seus participantes não se deixam afetar pelo outro e pelas diferenças, resistindo a mudanças" (Escossia, 2009, p. 691). Para Campos (2003) a cogestão é resultado e produto do aumento da potência de intervenção dos vários agrupamentos (equipe técnica, grupo vulnerável, comunidade, movimentos sociais, organizações, instituições) envolvidos em um problema sanitário relevante, que se expressa em projetos de intervenção elaborados de forma participativa.

Em todos esses movimentos, a construção compartilhada entre sujeitos que portam distintos interesses e se inserem de diversas formas na produção de saúde, pode ser percebida nos discursos institucionais, nos planos de intenção, não sendo perceptível no campo das práticas de saúde, que pela hipertrofia de seus aspectos tecnológicos (Escossia, 2003; Merhy, 2002), ainda aparece como um espaço com restrições ao compartilhamento com o outro.

O compartilhamento coletivo na produção de ideias, intenções, planos e projetos na esfera da teoria, da técnica ou da sabedoria prática iniciam-se no diálogo que acontece no encontro entre os diversos modos de andar a vida (Canguilhen, 1978), nas rodas de conversa com os coletivos sociais, na complementaridade entre as tecnologias científicas e populares e nos amplos sentidos que a saúde apresenta (Mattos, 2004). 
O diálogo pressupõe a existência de linguagem que possibilite a interação entre os participantes. A partir daí "es siempre conducido por una línea argumentativa que une un habla y outra, por uno sentido general (una totalidade comprensiva) donde cada habla gana significado"(Ayres, 2008, p.166), cujo sentido não é propriedade particular e é cada vez mais apropriado quanto mais se participa.

A construção compartilhada como recurso para compreender e transformar as ações de saúde desde suas dimensões epistemológicas, teóricas, conceituais, políticas e práticas tem como ponto de partida o conhecimento e as exigências normativas que são produzidas e acumuladas pela vivência subjetiva de cada um, tornando-se evidentes no encontro entre os sujeitos diversos.

Para que se produza esse conhecimento, Pedrosa (2006) salienta a necessidade da produção de situações interativas entre sujeitos de saberes e práticas, dispostos a refletirem posições previamente instituídas sobre o tema em discussão. Caso contrário, um interlocutor atua como sujeito vitimado, portador de demandas e o outro como salvador e portador de recursos, reproduzindo a clássica dominação de assimetria das relações de poder.

Nos encontros entre sujeitos que ocupam diferentes posições no campo da saúde, os limites entre autonomia política de cada participante e sustentabilidade dessa interlocução exigem contínua autovigilância a fim de que esse encontro possa ser autopoiético, capaz de produzir novas formas de relacionamento, de organização, de pensar a esfera pública e as lutas políticas (Merhy, 2004).

A perspectiva do AGAP foi oportunizar a reflexão e a necessidade de criar condições para uma nova forma de gestão na APS. Uma gestão voltada para as pessoas, com vozes ativas nos processos de decisões político-administrativas, presentes na elaboração dos programas, projetos, ações e/ou atividades, voltados, sobretudo, para a monitoria e avaliação dos resultados alcançados nos benefícios para os indivíduos, famílias e comunidades.

\section{Metodologia}

O Projeto AGAP pressupõe mudanças na cultura organizacional e a possibilidade do desenvolvimento de competências e habilidades das equipes gestoras em contextos políticos de grande instabilidade, revelando uma complexidade em que a decisão e as operações necessárias que envolvem as questões do que e como fazer não obedecem somente às regras das escolhas racionais orientadas pelo conhecimento científico (Potvin e Goldberg, 2007).

Para avaliar intervenções complexas em contextos desta natureza, Marinho e Chianca (2010), com base na dinâmica de sistemas complexos, utilizam modelos avaliativos adaptativos aos contextos, "capazes de identificar e revelar processos e resultados não lineares ou predeterminados, em que as relações de independência se fazem presentes, já não são os acordos e hierarquias que regem as relações e sim a autodeterminação dos indivíduos, as distintas formas de interação e os padrões comportamentais que possam ocorrer.". (Marinho e Chianca, 2010, p.4).

Dessa forma a avaliação do Projeto AGAP é colaborativa e participativa entre todos os parceiros envolvidos (Marinho e Chianca, 2010; Hartz e col., 2008; Van Meer e Edelenbos, 2006; Patton, 2007, 1997), considerando que o senso de propriedade sobre os produtos e inovações oriundos da avaliação e o compromisso de agir sobre são construídos ao longo do processo avaliativo, além de sua utilização como suporte para sustentabilidade das práticas inovadoras oriundas do Projeto AGAP, sendo os representantes das quatro Secretarias Estaduais de Saúde participantes sujeitos-chave no processo facilitado pelos pesquisadores.

Foi constituído um Comitê Gestor de Avaliação do Projeto AGAP composto por um interlocutor das Secretarias de Estado da Saúde e um representante do CONASS. Na pesquisa avaliativa, foram desenvolvidos os seguintes procedimentos metodológicos: análise documental, observação de encontros presenciais, oficina com o Comitê Gestor de Avaliação para apresentação e pactuação da proposta, oficinas de avaliação com os projetos locais, observação de unidades de saúde nos municípios, entrevistas semiestruturadas com sujeitos estratégicos dos níveis locais, regionais, nacional e internacional. Caracteriza-se, portanto, como uma pesquisa avaliativa que utiliza multimétodos (Creswell e Clark, 2007), permitindo a triangulação (Patton, 2007; Minayo, 2005) entre as fontes e conteúdos das informações, 
mediante a combinação de abordagens e de técnicas qualitativa e quantitativa (WHO, 1998).

Os momentos presenciais propiciados no desenvolvimento do projeto, assim como as oficinas de avaliação, foram considerados encontros que ocorreram entre profissionais locais, gestores e consultores envolvidos nos projetos, diferentes sujeitos portadores de horizontes normativos a respeito da saúde, da doença e da gestão, mediados pelo diálogo, base para a construção compartilhada de saberes e vivências apresentadas pelos participantes.

Transformaram-se em acontecimento com capacidade de desencadear outros movimentos resultados de ajustes, negociações e adaptações que definiram a implantação do AGAP em cada município, tendo como temas problematizadores: ações de educação permanente, monitoramento como ferramenta da atenção e de gestão em saúde; sistematização de evidências para o planejamento, avaliação e tomada de decisão; abordagem de gênero, cor e etnia; processo de produção e comunicação científica; desafios para o desenvolvimento da intersetorialidade e institucionalização das ações de APS.

Os pesquisadores, em estreita colaboração com as equipes de coordenação dos projetos, pactuaram a definição do escopo da avaliação, coleta de informações, discussão das análises e dos relatórios locais, parcial e final.

Neste artigo privilegiamos, como fonte de informações, as oficinas de avaliação dos projetos locais, realizadas nos Estados envolvidos com as equipes participantes, considerando que a experiência em gestão e avaliação de projetos tem evidenciado que os participantes necessitam de oportunidades para falar e escutar sobre: o processo de implementação, os aspectos que facilitaram e as barreiras enfrentadas para mudança de práticas, pois a maior parte da implementação requer um "ativismo" que compromete os espaços para a reflexão e produção de significados sobre o processo e as conquistas.

As oficinas aconteceram de setembro a outubro de 2010, com duração de doze (12) horas cada. 0 número de participantes variou de 6 a 22, seguindo uma agenda pactuada entre o Núcleo de Estudos em Saúde Pública - NESP/CEAM/UnB e as coordenações locais, compreendendo quatro momentos: i) Construção coletiva da linha do tempo; ii) Identificação de resultados e evidências; iii) Identificação de fatores facilitadores e dificultadores no processo; e iv) Dedução das lições aprendidas.

Atendendo aos princípios éticos que orientam a realização de estudos que envolvem seres humanos, a participação dos sujeitos nesta avaliação foi voluntária e se deu mediante a autorização verbal no início das entrevistas e nas oficinas. Os sujeitos concordantes foram esclarecidos da importância de sua participação neste trabalho, que não haveria riscos ou constrangimentos àqueles que recusassem participar e assinaram o Termo de Consentimento Livre e Esclarecido.

Para análise as informações obtidas nas oficinas foram confrontadas com as informações das entrevistas semiestruturadas realizadas e com a análise dos documentos do Projeto no sentido de construir parâmetros para identificação dos resultados e lições aprendidas (Alexandre e col., 2009) com base nos objetivos do Projeto AGAP, na sistematização de padrões comuns e nas relações estabelecidas por meio dos encontros presenciais e virtuais entre as parcerias. Segundo o Human Systems Dynamics Institute (2010), padrões são comportamentos ou eventos que se repetem ao longo do tempo e do espaço, emergentes das evidências do cotidiano dos serviços, oriundos do diálogo e da análise dos contextos locais.

Os resultados são apresentados na forma de síntese construída por meio das falas produzidas pelos sujeitos nas oficinas e entrevistas a respeito das facilidades e dificuldades de implementação do Projeto no contexto dos Estados envolvidos, as lições apreendidas pelas equipes locais e a perspectiva dos atores envolvidos.

\section{Resultados}

\section{Facilidades e dificuldades no contexto dos Estados}

Nos encontros os diálogos revelaram aspectos invisíveis da APS que passaram a ser evidenciados como fatores facilitadores e dificultadores, sistematizados em dois grupos: decorrentes do âmbito do Projeto AGAP (concepção, metodologia, integração, critério de avaliação, gestão financeira) e decorrentes do contexto local (político-administrativo, infraestrutura,). 
A metodologia de trabalho apresentada pelo projeto propiciou processos de formação estruturados com base nos problemas vivenciados na realidade, apropriação de tecnologias como o modelo lógico, definição dos problemas baseado em evidências, que geraram efeitos na relação entre os participantes, que se descobriram capazes de desencadear movimentos autônomos e iniciativas criativas diante das adversidades. Além disso, proporcionou apoio técnico, integração das áreas e colaboração institucional apontando possibilidades de intersetorialidade e sustentabilidade do projeto.

A temática da equidade em gênero e etnia foi considerada como uma proposta apresentada pelo projeto cuja contribuição estava na inovação e na oportunidade de interlocução com os movimentos sociais.

A gestão financeira do projeto foi considerada problemática e desestimulante, aliada às questões da lógica operacional: definição pouco precisa das ações a serem desenvolvidas, dificuldade no processo de seleção dos municípios participantes e composição dos grupos, construção do problema com bases em evidências muitas vezes de difícil acesso, incompatibilidade de agendas e cronograma das atividades, processo de premiação e a emergência de tratamento diferenciado entre alguns Estados por parte de parceiros.

Especificidades dos contextos locais decorreram da intensidade de manifestação de alguns problemas: dificuldades em operacionalizar a intenção de diminuir a iniquidade em gênero e etnia, reação negativa dos gestores municipais ao uso de evidências, não atualização e dificuldade de acesso às informações dos bancos de dados, evasão de participantes em decorrência de mudança na gestão local, falta de apoio de gestores, recursos financeiros insuficientes e difícil gestão no nível local.

\section{Lições aprendidas}

Aspectos considerados aprendizagens foram identificados a partir da pergunta-chave: que princípios, conselhos, estratégias podem ser listadas para orientar o planejamento de projetos similares a este? De maneira geral, os participantes identificaram o AGAP como dispositivo que promoveu aprendizados significativos para o trabalho e nesse processo foram evidenciadas potencialidades e possibilidades para a sustentabilidade de intervenções voltadas para a qualificação da APS:

Quanto aos aspectos fundamentais para a gestão da APS, as lições aprendidas foram relacionadas a: a) tradução e difusão dos atributos da Atenção Primária em Saúde - devem ser priorizados espaços e estratégias para recordar, difundir e sensibilizar gestores, trabalhadores, usuários sobre os atributos da APS, com potencialidade de despertar as equipes, reorientar práticas e provocar mudanças a partir da busca de sua concretização no cotidiano da gestão e dos serviços.

b) organização da gestão e da atenção de forma articulada, tema que gestores necessitam ser orientados sobre a importância de valorizar e investir no compromisso da equipe local com base na identificação de necessidades e instrumentalização para o desenvolvimento do projeto; ter como base o planejamento a partir do diagnóstico da situação de saúde e utilização do marco lógico; estruturação do trabalho em equipe multidisciplinar que possibilite a elaboração de protocolos e diretrizes baseadas em evidências; reconhecer a necessidade de reflexão e monitoramento sistemático das ações.

c) processo de capacitação e fortalecimento da identidade profissional-indivíduo, grupal e institucional deve ser estruturado a partir do contexto local dos participantes e oportunizar espaços para favorecer a constituição da grupalidade, fortalecer relações interpessoais que constituem dispositivos pedagógicos para o trabalho em equipe e suaviza o processo; ter a evasão dos momentos presenciais monitorada para indicar substituições às vagas; explicitar, no momento de inscrição dos participantes, o comprometimento e o conjunto de atividades que serão requeridas; reconhecer a importância da capacitação periódica das equipes; realizar negociação prévia com gestores e gerentes a respeito do tempo de dedicação ao AGAP e outras ações estratégicas para projetos no município; propiciar o desenvolvimento e combinação de capacidades/atributos cognitivos, psicomotores e afetivos dos gestores, trabalhadores e usuários visando a identificação e busca de soluções para os problemas encontrados; fortalecer a estima, letramento, capacidade argumentativa e de atuação individual dos profissionais; estimular mecanismos de solidariedade, trabalho em equipe, 
exercício do poder e tomada de decisão com os outros visando o fortalecimento grupal e institucional.

d) participação e construção coletiva significa o envolvimento de diversos atores sociais (gestores, trabalhadores, população e lideranças locais) e composição de equipes com representantes das diferentes áreas do setor saúde e dos diferentes âmbitos de gestão (central, regional e local) fundamentais para o desenvolvimento e sustentabilidade das ações; recomenda-se o planejamento participativo e o fortalecimento da intersetorialidade mediante o envolvimento de diferentes setores governamentais e da sociedade civil.

e) institucionalização e sustentabilidade resulta da busca de gestores e trabalhadores para a institucionalização das ações dos projetos para a garantia da continuidade mesmo diante das constantes mudanças de gestores e rotatividade dos profissionais.

f) Investimento e financiamento servem como modelo para implantação em todos os municípios de projetos de baixo custo e com evidências de efetividade, condicionado a garantias financeiras e mecanismos de execução dos recursos bem definidos.

\section{Os resultados do AGAP na ótica dos participantes}

A metodologia de avaliação permitiu que as expressões dos participantes a respeito do significado do projeto em termos do fortalecimento da parceria Brasil/Canadá, da organização do processo de educação permanente, metodologias e técnicas de informação e comunicação e possibilidades da sustentabilidade das intervenções municipais fossem aprendidas a partir das oficinas de avaliação e entrevistas realizadas e sistematizadas em quatro eixos.

No primeiro eixo, sobre a parceria internacional Brasil-Canadá, foram identificadas necessidades de escolher bem áreas afins entre os parceiros; mapear áreas de expertise da entidade canadense que poderiam ser aproveitadas, incluindo outras instâncias da própria Universidade de Toronto (gestão pública, avaliação, políticas públicas e de saúde, liderança, intervenções para mudança comportamental) e identificar aspectos específicos do apoio à atenção básica (ferramentas de diagnóstico e protocolos clínicos) e tecnologias de comunicação na assistência (telemedicina).

Não houve consenso sobre a fortaleza do suporte da instituição parceira canadense, principalmente no que diz respeito à gestão, considerando que sua contribuição na aquisição de competências em gestão/gerência se aplica em um contexto diferente dos Estados do Nordeste do Brasil.

Os entrevistados reconheceram carência de melhor dimensionamento da demanda brasileira, consideraram fundamental a comunicação do modus operandi das instituições acadêmicas canadenses e a necessidade peremptória de tradução para os docentes estrangeiros que não tenham competência linguística em português, sugerindo, para futuras intervenções, mapeamento de necessidades e de expertises que seriam contatadas e sensibilizadas para definição coletiva das responsabilidades de cada participante.

Um segundo eixo enfocou questões da organização de conteúdos no curso. Foi constatada diversidade entre os participantes quanto à sua formação, diferenças no domínio de ferramentas de informática e compreensão de conceitos básicos como os referentes aos indicadores de saúde. Na percepção de um dos entrevistados, perdeu-se muito tempo em decorrência de os participantes encontrarem-se em momentos diferentes nesses aspectos, sendo, necessário nivelamento inicial ou um maior tempo para esse nivelamento no módulo inicial.

Um terceiro eixo foi a importância que assumiu o componente de comunicação e informação. Foi sugerida a ampliação do componente da comunicação com a comunidade, reconhecida como uma das áreas em que se expressa melhor a experiência canadense, abrangendo a comunicação dos serviços de saúde com a população, os processos de educação em saúde e de participação comunitária. No quarto e último eixo, relacionado com a sustentabilidade, foi identificado o papel estratégico do Ministério da Saúde em acompanhar mais próximo com suas áreas técnicas o andamento dos projetos e assessorar.

\section{Discussão}

Apesar de ter proporcionado a produção de subjetividades de grupo entre os participantes dos projetos de intervenção, elementos agregadores em torno dos quais se expressavam desejos e necessidades, prevaleceu uma ótica mais tecnicista. Essa modelagem distanciou a participação da população e da 
gestão na construção do problema a ser enfrentado, evidenciado pela pouca referência a diálogos com movimentos da sociedade civil e os conflitos emergentes com a gestão local.

Esta predominância técnica dificultou a abordagem da promoção da equidade em gênero e etnia nas ações dos projetos, inclusive naqueles que tratavam de questões relativas à saúde da mulher. A questão étnica, a despeito do reconhecimento de sua importância, foi abordada de forma periférica nos processos formativos e gerou ambiguidade na compreensão restrita de "acesso para todas as etnias".

A abordagem em gênero considerada inovadora e importante não encontrou factibilidade nos contextos específicos de intervenção. Este distanciamento decorre da "relação de origem da saúde coletiva com os saberes da biomedicina, que operam sobre o corpo, muitas vezes a dimensão subjetiva e a maneira singular com que cada um a exerce foram negadas ou abstraídas. Deste modo, os atravessamentos do gênero na constituição do sujeito tornaram-se invisíveis na área”. (Villela e Monteiro, 2009 p. 944).

A despeito da tradição brasileira ao discutir sobre determinação social no processo saúde-doença, compreende-se que o enfrentamento dos Determinantes Sociais da Saúde, muitas vezes, encontra-se apenas no discurso, com poucas ações concretas, consequentemente com poucos indicadores de impacto sobre as iniquidades, principalmente às relacionadas a gênero e etnia/raça/cor. Para Nogueira (2009), não é suficiente correlacionar estatisticamente condições sociais e sanitárias, seguindo modelo de causalidade das ciências naturais porque os fenômenos são naturalizados como fatores causais das iniquidades, sem fundamentação do ponto de vista da justiça e da desigualdade.

A ausência da reflexão social e política a respeito das iniquidades em saúde e diálogo com os movimentos da sociedade civil reduziram a possibilidade de construir a intervenção considerando os desejos e necessidades dos excluídos.

As propostas de intervenção na forma de projetos foram resultados de processos coletivos de construção. Neste sentido o grupo envolvido em cada projeto, durante o tempo de desenvolvimento do AGAP, tornou-se um coletivo organizado, ou seja, um agrupamento que tem como objetivo e como ta- refa a produção de algum bem ou serviço (Campos, 200o). E, nesse processo, os coletivos organizados realizaram a tradução das regras e normas metodológicas do AGAP para as condições de viabilidade apresentadas em seus territórios.

O AGAP considerava a construção de problemas com base em evidências científicas, que se mostraram de difícil acesso, confiabilidade ou inexistência. Na distância entre o preconizado e o possível, foram desencadeados movimentos autônomos como a realização de inquéritos, atualização de banco de dados, melhoria nos sistemas de informação e reativação de Comitês de Controle da Mortalidade Materna.

0 processo de aprendizagem com base em problemas da realidade mostra-se adequado ao processo de formação de adultos, coerente com os pressupostos da educação permanente, entretanto, no caso da saúde, a participação de outros interessados na definição do problema e da estratégia é fundamental para o planejamento e gestão participativa. (Campos, 2003).

Carvalho e colaboradores (2001) consideram que a construção compartilhada de conhecimento implica um processo comunicacional e pedagógico entre sujeitos de saberes diferentes, convivendo em situações de interação e cooperação, um relacionamento entre pessoas ou grupos com experiências diversas, interesses, desejos, motivações coletivas. E, neste sentido é possível dizer que intervenções que envolvem forte componente pedagógico necessitam de um projeto político pedagógico que faça a mediação entre os objetivos e os processos, para superar o estágio de atualização técnica ou nivelamento dos profissionais em determinada tecnologia.

As maiores oportunidades para a produção compartilhada vivenciadas pelos participantes foram os encontros de monitoramento e avaliação e a construção do artigo científico. Refletir sobre a realidade na intencionalidade de modificá-la é pressuposto básico para a pedagogia problematizadora (Bordenave, 2002; Freire, 1996) e os encontros de monitoramento propiciaram este movimento para todos os envolvidos, permitindo a expressão da criatividade e da autonomia nas proposições de enfrentamento do problema.

As ações de informar, educar e comunicar que não foram originalmente tratadas de forma espe- 
cífica no AGAP ganham visibilidade a partir da necessidade dos processos formativos, do uso das tecnologias de informação e da adesão das pessoas aos projetos de intervenção.

Entretanto, inseridos na dimensão institucional que circunda o AGAP, as possibilidades da intervenção apresentavam limitações financeiras, gerenciais, além das flutuações dos contextos políticos locais, resultando em sentimento de frustração e impotência para os envolvidos.

\section{Considerações finais}

A experiência de construção compartilhada no desenvolvimento do Projeto AGAP leva a se considerar que problemas construídos circunscritos ao ambiente técnico podem apresentar alta validade interna, mas a validade externa, ou seja, para a sociedade que o reconhece como problema, somente é obtida por meio de ações de educação e comunicação.

Em relação às tecnologias de informação, as inovações ainda se encontram em processo de institucionalização no cotidiano da gestão, por deficiência de infraestrutura, falta de pessoal e formação. $\mathrm{O}$ uso de recursos comunicacionais virtuais precisa ser cultivado e fomentado nos serviços de saúde, como ferramentas de gestão e a comunicação com a comunidade.

O diálogo em cada um desses momentos, na visão dos participantes das oficinas de avaliação, produziu elementos que ampliaram o significado das práticas de APS em seus aspectos epistemológicos, quando das reflexões e questionamentos sobre conceitos, questões e fundamentação científica de decisões. Enriqueceu sua dimensão tecnológica na medida em que o planejamento e a gestão passaram a ser entendidos sob nova perspectiva, inclusive com a apropriação de técnicas e metodologias que davam suporte a decisões políticas e gerenciais.

A dimensão da práxis em APS mostrou-se importante redescoberta pelos participantes, possibilitando, no plano da intersubjetividade, a construção de relações afetivas, motivações, grupalidade entre os envolvidos por interesses e valores distintos, além de novos significados para o trabalho em APS. Foi a dimensão racional da práxis em APS que facilitou a discussão sobre as possibilidades da intersetoria- lidade na saúde e agregou, à produção de artigos e à sistematização das experiências, valor simbólico essencial para a afirmação dos atributos da APS.

No Brasil, existem espaços institucionalizados de participação da sociedade em todos os níveis de gestão como Conferências e Conselhos de Saúde. Esses espaços foram pouco evidentes na implementação do AGAP, reforçando a predominância da dimensão técnica do problema, reduzindo a dimensão subjetiva e política que envolve essas questões, excluindo a vivência e saberes dos usuários, circunscrevendo o conhecimento produzido ao grupo de técnicos.

Finalmente a relação de cooperação Brasil/ Canadá é promissora, entretanto precisa ser construída de forma mais cooperada e dialogada em que os objetos da cooperação sejam construídos de forma compartilhada, considerando que cooperação caracteriza-se por uma relação compartilhada estabelecida entre os participantes no desenvolvimento da aprendizagem e na realização de projetos de interesse comum (Carvalho, 20oo).

\section{Referências}

ALEXANDRE, V. P. et al. Implementação da intersetorialidade: parceria universidade-serviçocomunidade para a reorientação de políticas públicas. In: SPERANDIO, A. M. G. (Org.). $O$ processo de avaliação das experiências locais do Projeto de Ações Intersetoriais em Promoção da Saúde-AIPS: buscando as igualdades a partir das diferenças. Rio de Janeiro: Abrasco, 2009. p. 51-61. AVRITZER, L. Teoria democrática e deliberação pública em Habermas e Rawls. 200o. Disponível em: <http://biblioteca.clacso.edu.ar/ar/libros/ anpocsoo/gt19/oogt1912.doc>. Acesso em: 10 nov. 2007.

AYRES J. R. C. M. Para comprender el sentido práctico de las acciones de salud: contribuciones de la hermenéutica filosófica. Salud Coletiva, Buenos Aires, v. 4, n. 2, p. 159-172, 2008.

BORDENAVE, J. E. D. Além dos meios e mensagens: introdução à comunicação como processo, tecnologia, sistema e ciência. Petrópolis: Vozes, 2002. 
IBGE - INSTITUTO BRASILEIRO DE GEOGRAFIA

E ESTATÍSTICA. Síntese de Indicadores, 2008. Disponível em: <http://www.ibge.gov.br/ home/estatistica/populacao/condicaodevida/ indicadoresminimos/sinteseindicsociais2008/>. Acesso em: 5 maio 2009.

CAMPOS, G. W. S. Um método para análise e gestão de coletivos. São Paulo: Hucitec, 2000.

CAMPOS, G. W. Saúde paidéia. São Paulo: Hucitec, 2003.

CANGUILHEN, G. O normal e o patológico. Rio de Janeiro: Forense-Universitária, 1978.

CARVALHO, M. A. P. Análise de um ambiente construtivista de aprendizagem à distância: estudo da interatividade, da cooperação e da autonomia do curso de gestão descentralizada de recursos humanos em saúde. 200o. Dissertação (Mestrado em Educação em Ciências e Saúde) Universidade Federal do Rio de Janeiro, Rio de Janeiro, 2000.

CARVALHO, M. A. P.; ACIOLI, S.; STOTZ, E. N. O processo de construção partilhada do conhecimento: uma experiência de investigação científica do ponto de vista popular. In: VASCONCELOS, E. M. (Org.). A saúde nas palavras e nos gestos: reflexões da rede de educação popular em saúde. São Paulo: Hucitec, 2001, p. 101-114.

CONASS - CONSELHO NACIONAL DE SECRETÁRIOS DE SAÚDE. Histórico do Projeto. In: APERFEIÇOAMENTO EM GESTÃO DA ATENÇÃO PRIMÁRIA À SAÚDE : PROJETO AGAP. Documenta, Brasília, n. 22, p. 33-38, 2011.

CRESWELL, J. W.; CLARK, V. L. P. Designing and conduction mixed methods research. California: Sage, 2007.

EIBENSCHULTZ, C. Poder, salud y democracia. InTALLER LATINO-AMERICANO DE MEDICINA SOCIAL, 2, 1991, Caracas. Memorias... Ediciones del Rectorado. Caracas: Universad Central de Venezuela, 1991, p. 121-135.
ESCOSSIA, L. Por uma ética da metaestabilidade na relação homem-técnica. In: PELBART, P. P.; COSTA, R. (Org.). Cadernos de subjetividade: o reencantamento do concreto. São Paulo: Hucitec, 2003. p. 177-186.

ESCOSSIA, L. O coletivo como plano de criação na Saúde Pública. Interface: Comunicação, Saúde, Educação, Botucatu, v. 13, p. 681-694, 2009. Suplemento 1.

FREIRE, P. Pedagogia da autonomia: saberes necessários à prática educativa. São Paulo: Paz e Terra, 1996.

HARTZ, Z. M. A; SANTOS, E. M.; MATIDA, A. Promovendo e analisando o uso e a influência das pesquisas avaliativas: desafios e oportunidades ao se institucionalizar a avaliação em saúde. In: HARTZ, Z. M. A; FELISBERTO, E.; SILVA, L. M. V. (Org.). Meta-avaliação da atenção básica: teoria e prática. Rio de Janeiro: Fiocruz, 2008. p. 325-340.

HUMAN SYSTEMS DYNAMICS INSTITUTE. Frequently Asked Questions About Tools and Patterns of HSD .Disponível em: <http://www. hsdinstitute.org/about-hsd/what-is-hsd/faq-toolsand-patterns-of-hsd.html> Acesso em: 04 abr. 2010.

MARINHO, E.; CHIANCA, T. Relatório de avaliação do Projeto AIPS: ações intersetoriais em promoção da saúde. Rio de Janeiro: Ensp: Abrasco: CPHA, 2010.

MATTOS, R. A. A integralidade na prática (ou sobre a prática da integralidade). Cadernos de Saúde Pública, Rio de Janeiro, v. 20, n. 5, p. 14111416, 2004.

MERHY, E. E. Saúde: a cartografia do trabalho vivo. São Paulo: Hucitec, 2002.

MERHY, E. E. A loucura e a cidade: outros mapas (contra um modo de fabricar cidadãos), uma militância autopoiética. Campinas: Unicamp, 2004 .

MINAYO, M. C. (Org.). Avaliação por triangulação de métodos: abordagem de programas sociais. Rio de Janeiro: Fiocruz, 2005. 
NOGUEIRA, R. P. Determinantes, determinação e determinismo sociais. Saúde em Debate, Rio de Janeiro, v. 33, n. 83, p. 397-406, 2009.

PATTON, M. Q. Utilization-focused evaluation: the new century text. California: Sage, 1997.

PATTON, M. Q. Qualitative evaluation and research methods. California: Sage, 2007.

PEDROSA, J. I. S. Notas sobre a educação popular e política de educação permanente em saúde. Saúde em Debate, Rio de Janeiro, v. 3o, n. 73/74, p. 179188, 2006.

POTVIN, L.; GOLDBERG, C. Two roles of evaluation in transforming health promotion practice. In: O'NEILL, M. et al. Health promotion in Canada: critical perspectives. Toronto: Canadian Scholars' Press, 2007. p. 347-36o.

SANTOS, B. S. Estado e democracia: impasses num mundo globalizado In: CONGRESSO MUNDIAL DE SAÚDE PÚBLICA, 11.; CONGRESSO BRASILEIRO DE SAÚDE COLETIVA, 8., 20o6, Rio de Janeiro. Anais... Rio de Janeiro. ABRASCO, 2006. CD-ROM
TATAGIBA, L. Os desafios da articulação entre sociedade civil e sociedade política sob o marco da democracia gerencial: o caso da Rede Criança em Vitória-ES. In: SILVA, M. Z.; BRITO JUNIOR, B. T. Participação social na gestão pública: olhares sobre as experiências de Vitória-ES. São Paulo: Annablume, 2009. p. 145-193.

VAN DER MEER, F. B.; EDELENBOS, J. Evaluation in multi-actor policy processes: accountability, learning and co-operation. Evaluation: the International Journal of Theory, Research and Practice, London, v.12, n. 2, p. 201-218, 2006.

VILLELA, W.; MONTEIRO, S. A promissora expansão do uso da categoria gênero pela Saúde Coletiva Brasileira. Ciência e Saúde Coletiva, Rio de Janeiro, v. 14, n. 4, p. 994-995, 2009.

WHO - WORLD HEALTH ORGANIZATION. Regional Office for Europe. Health promotion evaluation: recommendations to policymakers. Copenhagen, 1998.

Recebido em: 02/07/2011

Reapresentado em: 12/12/2011

Aprovado em: 08/03/2012 